\title{
Impact of Smart City Planning and Construction on Economic and Social Benefits Based on Big Data Analysis
}

\author{
Zihan Zhao' ${ }^{1}$ and Yuhan Zhang $\mathbb{D}^{2}$ \\ ${ }^{1}$ School of Business, Central University of Finance and Economics, Beijing 100081, China \\ ${ }^{2}$ School of Mechanical and Manufacturing Engineering, University of New South Wales, Sydney 2052, Australia \\ Correspondence should be addressed to Yuhan Zhang; z5220064@ad.unsw.edu.au
}

Received 29 September 2020; Revised 24 October 2020; Accepted 28 October 2020; Published 10 November 2020

Academic Editor: Wei Wang

Copyright (c) 2020 Zihan Zhao and Yuhan Zhang. This is an open access article distributed under the Creative Commons Attribution License, which permits unrestricted use, distribution, and reproduction in any medium, provided the original work is properly cited.

\begin{abstract}
With the progress of urbanization, urban management is facing a series of challenges in the new situation. The scale of the city is growing, urban management problems are increasingly prominent, the urban population is showing a rapid growth trend, and various elements of urban infrastructure management, such as rapid growth and urban expansion, have increased the load of urban infrastructure. To make overall planning for urban transportation, municipal administration, economic industry, and public service, intelligent urban planning and construction came into being. Big data technology provides important support for the construction and development of smart city, which is not only an effective means to improve the design of smart city, but also the premise for the development of smart city. Therefore, this paper first introduces the characteristics of smart city, analyses the application of big data technology in smart city design, and finally evaluates the impact of smart city planning and construction based on big data on economic and social benefits.
\end{abstract}

\section{Introduction}

Nowadays, the urbanization process is getting faster and faster. This process has brought many new challenges to urban development. The ensuing "urban diseases" in population, resources, transportation, and environment have severely restricted and hindered the development, have become a bottleneck for urban development, and have also become a dilemma for city managers to solve [1]. Smart city is a new form of urban construction that has emerged gradually in the process of the rapid development of a new generation of information technology, the widespread use of informatization in urban management practices, and the promotion of changes in urban management methods [2]. Through the extensive application of the new generation of information technologies such as the Internet of things, cloud computing, big data, and artificial intelligence, the government has continuously improved the level of urban intelligent management services in the fields of planning, construction, industry, people's livelihood, and society and made the city run more smoothly, convenient, and efficient [3]. Smart city construction is used by many major developed countries as an important strategy for stimulating economic development and maintaining long-term competitive advantages. It has become the new model and trend of urban development in the world today.

From the perspective of foreign developments, major developed countries are proactively deploying smart construction, constantly launching smart development strategies suitable for their national conditions, focusing on smart manufacturing to continue to step up strategic planning layout, encouraging the opening of data resources to promote social application development, and accelerating the promotion of the economy information development in all areas of society [4]. The European Union has formulated a smart city framework; the United States has proposed a smart city-related economic stimulus plan, which mainly covers strengthening infrastructure construction and promoting application projects; Japan has launched the national IT development plan for three consecutive times; South 
Korea has launched U-city's national strategy planning; Singapore has also proposed a "smart country" construction strategy [5]. According to incomplete statistics, more than 1,000 smart cities have been launched or are under construction around the world and will continue to grow in the future. From the perspective of domestic development, with the rapid increase in the concept, smart cities have attracted the attention and pursuit of major cities in recent years, and more and more cities have adopted it as a strategic choice for local social and economic transformation and development $[6,7]$.

Smart service support based on cloud computing and the big data cloud platform of the Internet of things can provide higher technology for the construction of smart cities and make it more integrated with the social attributes of cities. To this end, this article combines the reality and explores the application of smart city construction from the perspective of big data; collects the data information related to city operation based on the big data and collects and analyses the data after extracting, converting and loading the data, to obtain accurate city information content; and analysed the impact of smart city planning and construction on economic and social benefits and played a positive role in making smart city planning and construction more scientific and reasonable.

\section{Planning and Construction of Smart City in the Era of Big Data}

2.1. Definition of Smart City. Smart city is a product of the development of modern high technology. Its development mainly depends on the continuous progress of science and technology. Now we live in an information society, and all kinds of living conditions are developing to a high level $[8,9]$. Smart city is now a collection of higher concepts. It is the new trend of urban development, in line with the current social trend, and conducive to the high-level development of our society. Smart city not only includes most of the characteristics of digital city, but also uses modern information and communication technology to integrate and analyse various key factors in the process of urban development, and, according to these key factors, it adopts corresponding intelligent solutions for people's livelihood, urban services, and other aspects of the city [10]. The core of the concept of smart city is to make full use of modern technology and information means, integrate all factors, and make the city more reasonable and scientific in operation. And this idea is also conducive to the development and progress of a harmonious society, to achieve the goal of harmonious development of the city and the improvement of people's living standards.

2.2. Basic Structure of Smart City. The essence of smart city design is to use big data technology to process urban information intelligently. In real life, every citizen and every unit will feel the convenience brought by smart city to our lives. The whole design and construction process of smart city is quite complex, involving many departments, cross regions, and data cross types [11]. Realizing the management of big data business, massive traffic data, detection of geographic location data, environmental data, medical data, government data, education data, and public security data, realizing the comprehensive, real-time, high system data collection, storage, analysis, and mining, and making every citizen in urban life feel the superiority of the environment, the city becomes more and more "intelligent," and every citizen will be able to make more "intelligent" use of information and make more "intelligent" judgments and responses to the world and others [12]. The system architecture design of smart city based on big data technology must be based on the existing cities, introducing big data technology into urban construction to ensure that the designed smart city can meet the needs of citizens. The system architecture of smart city based on big data technology proposed in this paper generally includes application layer, platform layer, network layer, and perception layer, and the application layer includes smart government, smart transportation, smart medical care, smart economy, smart manufacturing, safe city, and smart community; platform layer mainly involves data storage, data integration, data standards, and data modelling; network layer involves communication network, Internet, and Internet of things; perception layer mainly includes government system, intelligent terminal, and camera [13]. Each system should conform to its own standard system, to ensure that the designed smart city has higher security, better practicability, lower operation, maintenance cost, and so on. The system architecture of smart city is shown in Figure 1.

2.3. Planning and Design of Smart City Based on Big Data Technology. The key to the development and construction of smart city is to build a big data processing platform, which can provide better environmental support for the data processing of smart city. The cloud platform in smart city has the function of using a large amount of data to provide urban application services such as integration, analysis, management, mining, and support according to the attributes of urban social services. The development of smart city needs a lot of unstructured data information [14]. Traditional relational database cannot deal with these data information effectively. Under the function of cloud platform, it can build a platform to deal with these data in a unified way [15]. At the same time, it can provide more comprehensive data services for smart city with the distributed data framework and data linear expansion function of cloud computing platform support. The construction of smart city technology system based on big data cloud platform is shown in Figure 2.

The development of a smart city needs to combine numerous social information. The amount of information and data included in the development process of each city is quite large. Only by thoroughly understanding and perceiving the information and data required by the city can we better utilize the many problems that exist in the process of smart city construction. Only then can we formulate relevant scientific plans and policies to solve it [16]. In short, the 

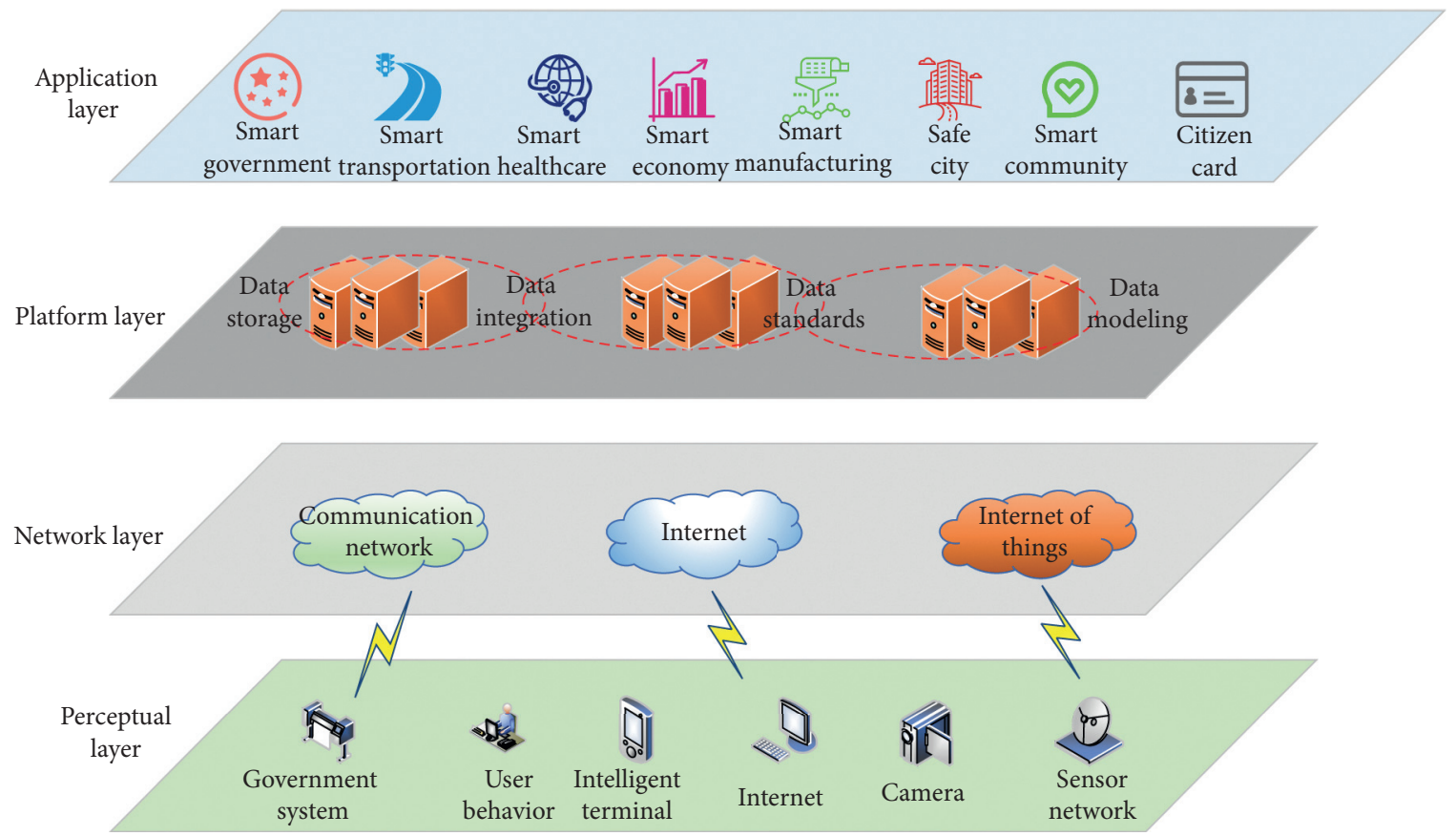

Figure 1: The system architecture of smart city.

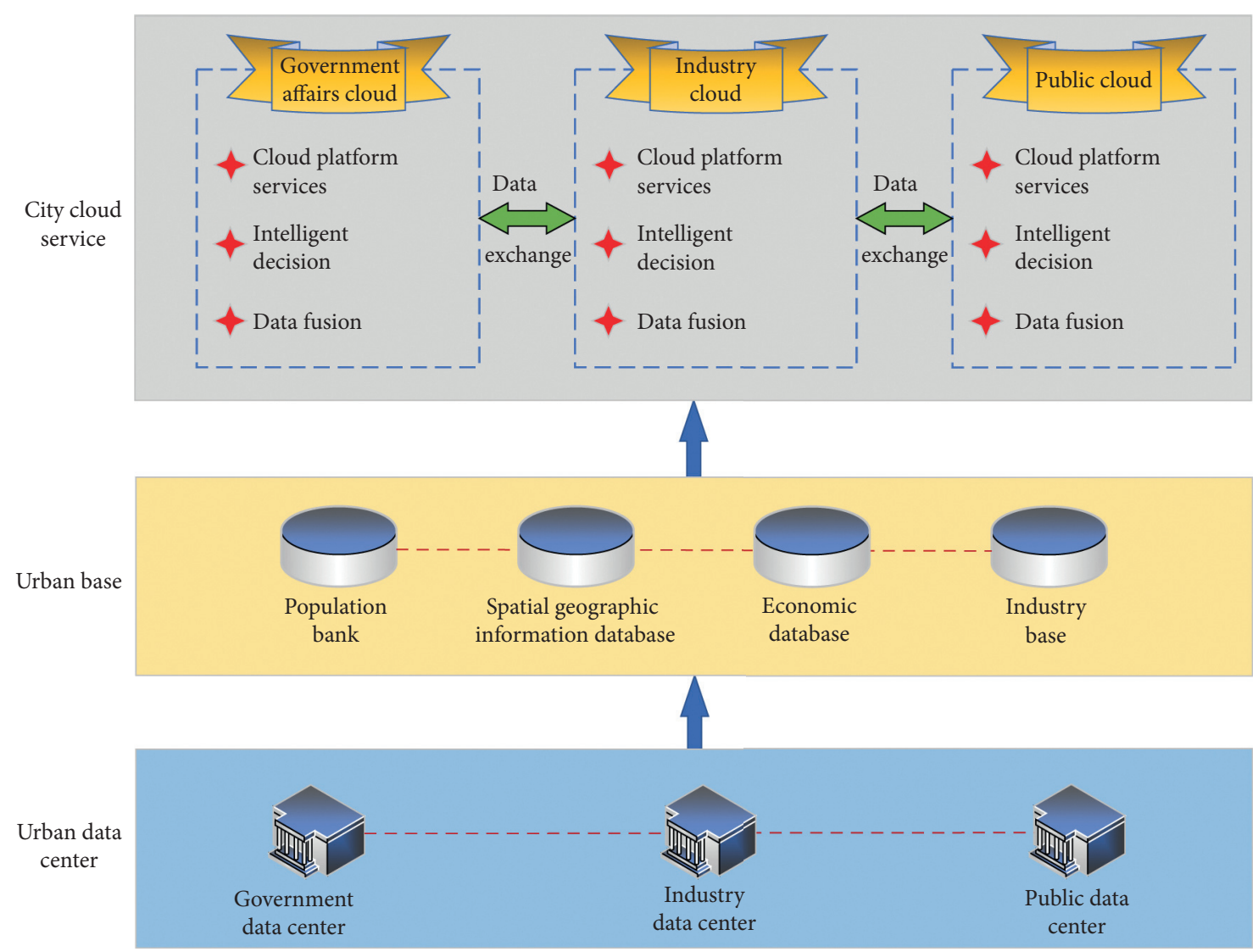

FIGURE 2: The construction of smart city technology system based on big data cloud platform.

construction of smart cities needs to be fully integrated with the current high-tech, so that we can better receive highaccuracy and huge amounts of information data for the construction of smart cities, provide sufficient scientific information basis, then conduct detailed research and analysis on the information, and finally get the information 
needed for the development of smart cities [17]. However, the broad coverage of the information-aware network we are talking about does not mean comprehensive analysis and integration of the city's information data, but only the integration of key factors that have an impact on urban development [18]. If the city information is collected comprehensively, it will not only consume a lot of manpower and material resources but also will not have a beneficial impact on the smart city.

The information network occupies a crucial position in the construction of smart cities, mainly the establishment of multiple information networks, and plays a good role in society. To achieve the goal of "deep interconnection," it is necessary to form a linkage of multiple information networks to achieve the purpose of interoperable access between information and scheduling operations between access devices and to achieve the three-dimensional and integration of information resources [19]. In the opinion of some scholars, we can find that the nodes of the network are very important to a network system. When developing a smart city, we can learn from it that multiple independent and separated small information networks are integrated into one large network [20]. Only in this way can the degree of interaction of city information be greatly improved, and this move can also effectively increase the value of members in the information network, so that the development speed of the smart city will be greatly improved, because the quality level of network information directly determines the development of the current smart city and provides the development of the smart city, scientific guidance, and motivation.

In the process of using information, intelligent processing is only one stage, not the end stage of the whole process. The development of smart city requires each city to establish a high-level information application and sharing platform, so that the information resources shared in the society can be analysed and applied at a high level, so as to make better use of these information [21]. In the process of realizing the value-added information, the speed and quality of smart city development are correspondingly improved, and the living environment of people is improved quality, not focusing on the unified allocation of information and deepening the degree of information interaction between each other through the information application platform, which is not only conducive to give full play to the characteristics of smart cities but also improve information exchange and communication, and promote the emergence of new development models.

The main purpose of smart city design based on big data technology is to realize the intelligent management of the city. At present, the design of smart city based on big data technology needs further development and has not reached a very mature stage. Therefore, there is no unified standard for the system integration of smart city based on big data technology. The overall design of smart city based on big data technology is shown in Figure 3.

The application layer of smart city design based on big data technology is mainly used to realize various public services, and is also the final content fed back to all citizens.
The public service content mainly includes smart government, smart transportation, smart medical treatment, smart economy, smart manufacturing, safe city, smart community, and smart public security. The data service layer of smart city design based on big data technology is mainly used to realize the sharing of all kinds of data in smart city. In this layer, there is a central sharing library, which is mainly used to store all kinds of smart data and realize the information exchange of smart data. This layer mainly provides data statistics services, data analysis services, data mining services, space-time services and various kinds of services data publishing, data collection, and business model services. The exchange and fusion layer of intelligent urban design based on big data technology is mainly used to realize the fusion and exchange of various data; the front exchange layer of intelligent urban design based on big data technology exchanges data with the exchange and fusion layer.

\subsection{Application Advantages of Big Data Platform in Smart} City. The advantages of big data platforms in smart city planning and construction are mainly reflected in the following aspects: (1) through the big data platform and the full life cycle management of smart city data collection, integration, analysis, and application; (2) through big data, where platform realizes data integration, comparison, and verification of various government affairs departments and realizes data uniqueness, accuracy, and data exchange and sharing; (3) realizing the openness of government affairs information through the big data platform; (4) realizing the health epidemic situation prediction and the forecast and analysis of public opinion prediction and market economy; (5) providing smart government decision-making based on big data platform: industrial decision-making, macrocontrol, and emergency command; "government decision-making platform" provides various decision-making information and problem solutions for the government, thereby improving the quality and efficiency of decision-making; based on the visual government decision-making platform, various models and technologies are used to qualitatively and quantitatively analyse government data to provide managers with a basis for decision-making; (6) real-time corporate credit supervision through big data platforms; (7) the data platform realizing the coordinated development of the big data industry, implementing the benefits of information with the idea of big data operations, and driving information consumption. The flow chart of management of the whole data life cycle of smart city is shown in Figure 4.

\section{Evaluation of the Impact of Economic and Social Benefits}

3.1. Analytic Hierarchy Process. Determine the content and scope of the evaluation, evaluation indicators, and relationships and establish a hierarchical model of project evaluation accordingly. Analyse the relationship between various factors in the system and decompose the related factors into several 


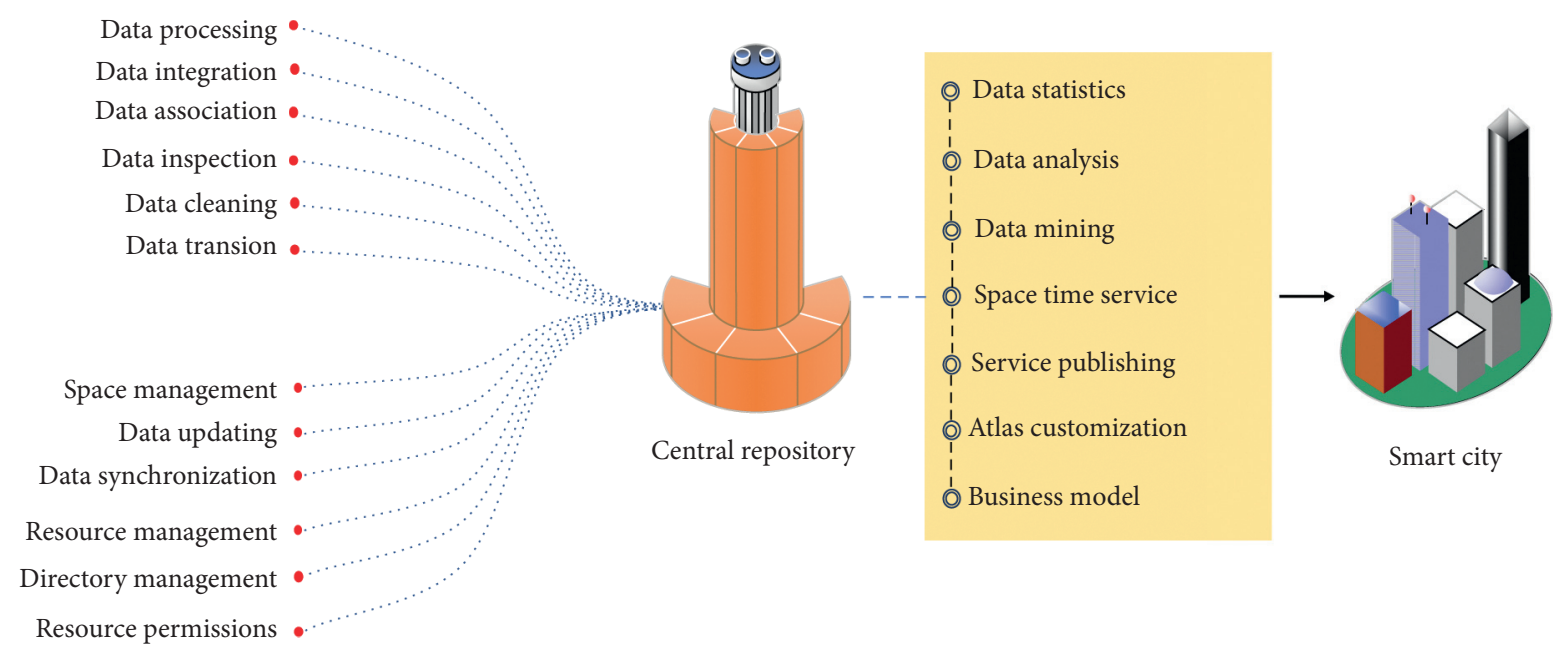

FIgURE 3: The overall design of smart city based on big data technology.

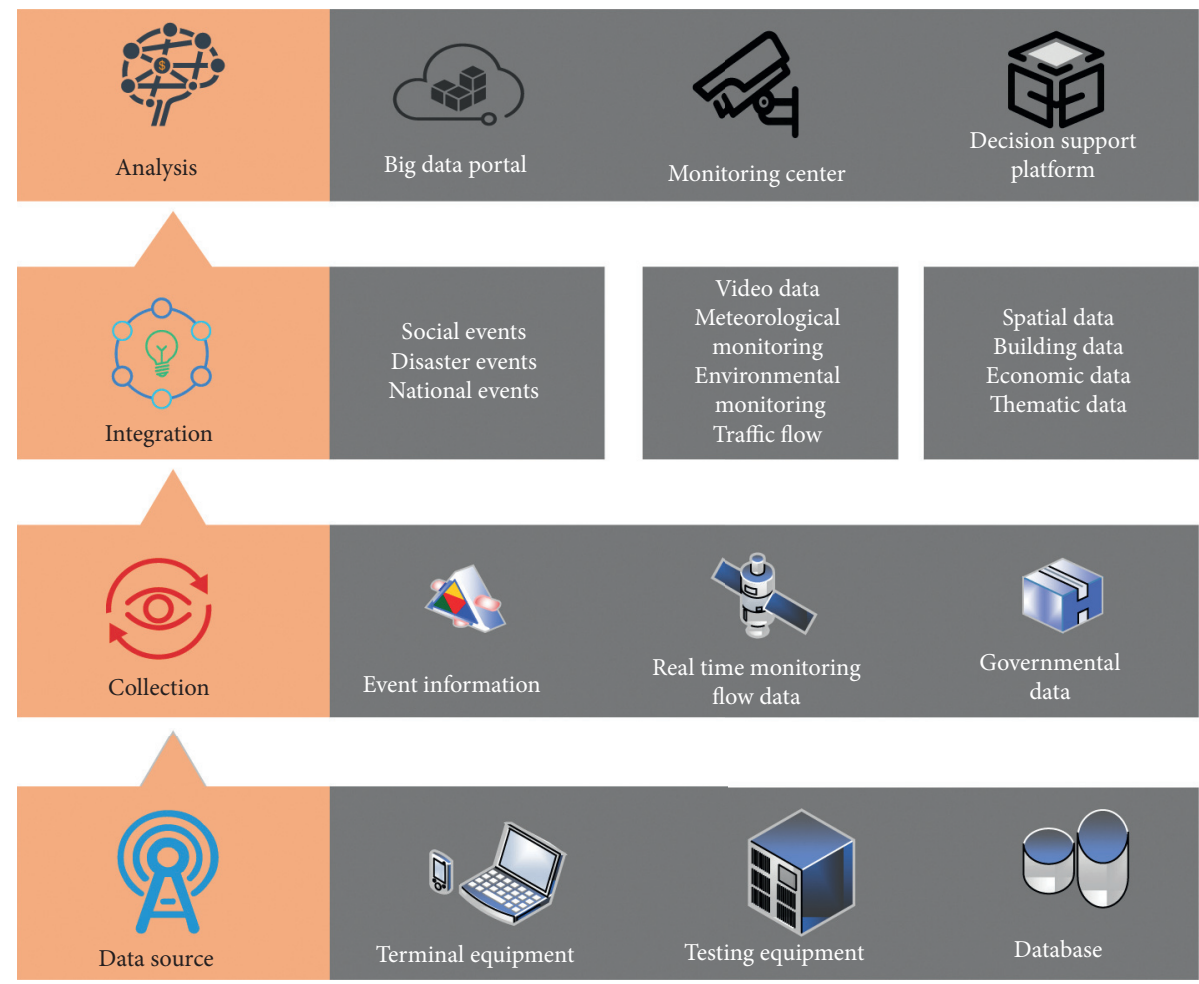

Figure 4: Management of the whole data life cycle of smart city.

levels according to different attributes. The factors of the same layer are subordinate to the factors of the upper layer and at the same time dominate the factors of the next layer [22]. There is a vertical interaction between factors at each level; after the establishment of the hierarchical hierarchy structure, the affiliation of various factors between the upper and lower layers is determined and then the ordering problem in the hierarchy. Starting from the second level of the hierarchical structure model, compare the importance of each factor at the same level relative to a criterion or a target at the previous level and use the pairwise comparison method and 1-9 scale to quantify the judgment importance levels given by scatty and their assignments are shown in Table 1.

If $n$ factors are compared with each other, a positive reciprocal matrix for pairwise comparison judgment is formed:

$$
A=\left(a_{i j}\right)_{n \times n}
$$

According to the judgment matrix and relative weight, calculate the weight of each factor relative to the importance order of the upper level factors under a single standard. It can be summarized as the problem of calculating the 
TABLE 1: Scale table of importance judgment.

\begin{tabular}{lr}
\hline Scaled quantized value & Meaning \\
\hline 1 & Factor $i$ and factor $j$ are equally important to an attribute \\
3 & Factor $i$ is slightly more important than factor $j$ to an attribute \\
7 & Factor $i$ is more important than factor $j$ to an attribute \\
9 & Factor $i$ is strongly more important than factor $j$ to an attribute \\
$2,4,6,8$ & Factor $i$ is slightly more important than factor $j$ to an attribute \\
\hline
\end{tabular}

characteristics and eigenvectors of judgment matrix. Calculate the $n$th root $\beta$ of the product of all elements in each row of judgment matrix $A$ and get the vector.

$$
\beta=\left(\beta_{1}, \beta_{2}, \ldots, \beta_{n}\right)^{T} \text {. }
$$

Among them,

$$
\beta_{i}=\sqrt[n]{\coprod^{n} a_{i j}}, \quad i=1,2, \ldots, n .
$$

Normalize the vector $\beta$ to get the weight vector.

$$
\theta=\left(\theta_{1}, \theta_{2}, \ldots, \theta_{n}\right)^{T}
$$

Among them,

$$
\theta_{i}=\frac{\beta_{i}}{\sum_{i=1}^{n} \beta_{i}}, \quad i=1,2, \ldots, n .
$$
A.

Calculate the maximum eigenvalue of judgment matrix

$$
\gamma_{\max }=\frac{1}{n} \sum_{i=1}^{n} \frac{(A \theta)_{i}}{\theta_{i}}, \quad i=1,2, \ldots, n
$$

It comes down to calculating the weight of each level factor relative to the total objective of system evaluation, that is, the combined weight. The hierarchical total ranking needs to be carried out layer by layer from top to bottom and the combined weight of each level factor relative to the total objective can be obtained by weighting calculation from top to bottom.

In the process of analysing hierarchy process, if the evaluation matrix is given artificially, the evaluator cannot give a very accurate judgment, and then the evaluation matrix established is difficult to have complete consistency, so consistency check is needed to approach the evaluation matrix and acceptable standards of conformity. In the construction of judgment matrix, the less the comparison factors, the higher the accuracy of judgment results, and vice versa. In other words, the more dimensions a judgment matrix has, the more likely it is to deviate from consistency. In order to achieve approximate consistency, the residual eigenvalues of the judgment matrix other than the maximum eigenvalues are as close to zero as possible, and the consistency test index used is the consistency ratio. Among them, $\varphi$ is called the consistency index, $\varphi=\left(\left(\gamma_{\max }-n\right) /(n-1)\right), n$ is the order of judgment matrix,
TABLE 2: Standard table of consistency index of reciprocal matrix. \begin{tabular}{llllllllll}
\hline Matrix order & 1 & 2 & 3 & 4 & 5 & 6 & 7 & 8 & 9 \\
\hline
\end{tabular}

\begin{tabular}{llllllllll}
\hline$\theta$ & 0 & 0 & 0.57 & 0.89 & 1.13 & 1.35 & 1.52 & 1.56 & 1.57 \\
\hline
\end{tabular}

and any number from 1 to 9 scale is taken by random method to form the consistency index of reciprocal matrix. Standard table of consistency index of reciprocal matrix is shown in Table 2.

\subsection{Construction of Comprehensive Economic and Social} Benefit Evaluation Model. The methods of determining index weight mainly include subjective weight, objective weight, and combination of subjective and objective methods. Subjective weight method is a method that the evaluator emphasizes each index according to his/her knowledge and experience and determines the index weight subjectively, including Delphi method and analytic hierarchy process. Subjective weighting method is not objective, but more explanatory [23]. The objective weighting method is that the evaluator calculates the index according to the original information of each index and automatically obtains the data and weight according to certain rules or rules. Although the weighting accuracy determined by objective weighting method is relatively high, sometimes it violates the actual situation. In practice, according to the weight determined by objective weighting method, the most important index may not necessarily have the maximum weight, and the least important index may have the maximum weight. According to the characteristics of social benefit evaluation indexes of reservoir resettlement, this paper considers that the analytic hierarchy process method of subjective weighting method is more logical and practical [24]. When using analytic hierarchy process to determine the weight of various indicators in the measurement system, first solve the problem, establish a hierarchical model, then establish a decision matrix, and then establish a hierarchical single ordering and consistency.

Compared with the general objective $A$ of the economic and social benefit evaluation of smart city, there are three indicators in the first level of the indicator layer, namely, the impact evaluation on social economy, the impact evaluation on local government, and the impact evaluation on the public $\left(B_{1}, B_{2}, B_{3}\right)$. The relative importance matrix is obtained by comparing the importance scales. Relative importance matrix is shown in Table 3. 
TABle 3: Relative importance matrix.

\begin{tabular}{lccc}
\hline Overall evaluation $A$ & Impact on regional economy $B_{1}$ & Impact on local government $B_{2}$ & Impact on the public $B_{3}$ \\
\hline Impact on regional economy $B_{1}$ & 1 & 0.5 & 0.5 \\
Impact on local government $B_{2}$ & 2 & 1 & 1 \\
Impact on the public $B_{3}$ & 2 & 1 & 1 \\
\hline
\end{tabular}

TABLE 4: Calculation of weight vector $\theta$.

\begin{tabular}{lccc}
\hline Judgment matrix row & $U_{i}=\prod_{j=1}^{n} a_{i j}$ & $\beta_{i}=\sqrt[n]{\prod_{j=1}^{n} a_{i j}}$ & $\theta_{i}=\left(\beta_{i} / \sum_{i=1}^{n} \beta_{i}\right)$ \\
\hline Impact on regional economy $B_{1}$ & 0.24 & 0.6401 & 0.203 \\
Impact on local government $B_{2}$ & 2 & 1.2598 & 0.399 \\
Impact on the public $B_{3}$ & 2 & 1.2598 & 0.399 \\
\hline
\end{tabular}

Through formula calculation, weight vector $\theta$ is obtained, as shown in Table 4.

The so-called hierarchical single ordering is to solve the largest eigenvalue $\gamma_{\max }$ and its eigenvector $\theta$ of the judgment matrix $M$. The vector value of the weight vector $\theta$ here represents the weight of each index relative to the previous level, rather than the total relative weight.

$$
\begin{aligned}
A \theta & =\left(\begin{array}{ccc}
1 & 0.5 & 0.5 \\
2 & 1 & 1 \\
2 & 1 & 1
\end{array}\right)\left(\begin{array}{l}
0.203 \\
0.399 \\
0.399
\end{array}\right)=\left(\begin{array}{l}
0.602 \\
1.204 \\
1.204
\end{array}\right), \\
\gamma_{\max } & =\sum_{i=1}^{3} \frac{(A \theta)_{i}}{n \theta_{j}}=\frac{0.602}{3 \times 0.203}+\frac{1.204}{3 \times 0.399}+\frac{1.204}{3 \times 0.399}=3.0001 .
\end{aligned}
$$

Consistency test is as follows:

$$
\varphi=\frac{\gamma_{\max }-n}{n-1}=\frac{3.0001-3}{3-1}=0.00005
$$

According to the above steps, the weights of indicators at all levels in the entire evaluation indicator system can be calculated. Weight of all levels of indicators in the evaluation index system is shown in Table 5 .

Set the judgment model and set $P=\left(P_{1}, P_{2}, P_{3}, \ldots, P_{i}\right)$ and $Q=\left(Q_{1}, Q_{2}, Q_{3}, \ldots, Q_{j}\right)$, where $P$ is the indicator set and $Q$ is the evaluation set. Each index set up in the above social benefit evaluation system shall be graded according to the level of set $R=$ (good, general, poor). The evaluation scores of multiple auditors or experts are averaged after statistical processing to obtain the scores of various indicators.

The comprehensive evaluation method for the economic benefits of smart city planning and construction is to use the expert evaluation method. First, based on introducing the relevant background, forecast data, and conditions of the project, the experts make a fuzzy evaluation of the reflected problem factors, and then the experts' evaluation comments are collected. A total of 20 experts participated in the scoring. The results of the expert evaluation are shown in the table below. The numbers in the table are the ratio of the number of experts who agree with this evaluation to the total number of experts. Expert's review results are shown in Table 6.

The evaluation matrix $R$ can be obtained from the table.

$$
R=\left[\begin{array}{ccc}
0.4 & 0.3 & 0.3 \\
0.5 & 0.3 & 0.2 \\
0.2 & 0.4 & 0.4 \\
0.5 & 0.3 & 0.2 \\
0.7 & 0.2 & 0.1 \\
0.8 & 0.2 & 0 \\
0.5 & 0.3 & 0.2 \\
0.4 & 0.2 & 0.4 \\
0.5 & 0.2 & 0.2
\end{array}\right] .
$$

In this study, the comprehensive evaluation results of economic benefits of planning and construction of smart city are as follows: 
TABLE 5: Weight of all levels of indicators in the evaluation index system.

\begin{tabular}{|c|c|c|c|c|c|c|c|}
\hline $\begin{array}{l}\text { Impact on regional } \\
\text { economy } B_{1}\end{array}$ & $\begin{array}{l}\text { Employment } \\
\text { efficiency }\end{array}$ & $\begin{array}{l}\text { Resource } \\
\text { utilization }\end{array}$ & $\begin{array}{l}\text { Improvement of economic } \\
\text { structure }\end{array}$ & $\begin{array}{l}\text { Improvement of } \\
\text { residents' life }\end{array}$ & $U_{i}$ & $\beta_{i}$ & $\theta_{i}$ \\
\hline Employment efficiency & 1 & 3 & 3 & 1 & 9.00 & 1.74 & 0.38 \\
\hline Resource utilization & $1 / 3$ & 1 & 1 & $1 / 3$ & 0.12 & 0.58 & 0.13 \\
\hline $\begin{array}{l}\text { Improvement of economic } \\
\text { structure }\end{array}$ & $1 / 3$ & 1 & 1 & $1 / 3$ & 0.12 & 0.58 & 0.13 \\
\hline $\begin{array}{l}\text { Improvement of residents' } \\
\text { life }\end{array}$ & 1 & 3 & 3 & 1 & 9.00 & 1.74 & 0.38 \\
\hline
\end{tabular}

TABLE 6: Expert's review results.

\begin{tabular}{|c|c|c|}
\hline Evaluation factors & Evaluation & Evaluation value \\
\hline \multirow{3}{*}{ Investment payback period $C_{1}$} & Good & 0.4 \\
\hline & Moderate & 0.3 \\
\hline & Poor & 0.3 \\
\hline \multirow{3}{*}{ Net present value $C_{2}$} & Good & 0.5 \\
\hline & Moderate & 0.3 \\
\hline & Poor & 0.2 \\
\hline \multirow{3}{*}{ Internal rate of return $C_{3}$} & Good & 0.2 \\
\hline & Moderate & 0.4 \\
\hline & Poor & 0.4 \\
\hline \multirow{3}{*}{ Policy risk $C_{4}$} & Good & 0.5 \\
\hline & Moderate & 0.3 \\
\hline & Poor & 0.2 \\
\hline \multirow{3}{*}{ Economic risk $C_{5}$} & Good & 0.7 \\
\hline & Moderate & 0.2 \\
\hline & Poor & 0.1 \\
\hline \multirow{3}{*}{ Technology risk $C_{6}$} & Good & 0.8 \\
\hline & Moderate & 0.2 \\
\hline & Poor & 0 \\
\hline \multirow{3}{*}{ Social risk $C_{7}$} & Good & 0.5 \\
\hline & Moderate & 0.3 \\
\hline & Poor & 0.2 \\
\hline \multirow{3}{*}{ Improve environment $C_{8}$} & Good & 0.4 \\
\hline & Moderate & 0.2 \\
\hline & Poor & 0.4 \\
\hline \multirow{3}{*}{ Promote employment $C_{9}$} & Good & 0.5 \\
\hline & Moderate & 0.3 \\
\hline & Poor & 0.2 \\
\hline
\end{tabular}

$B=\left[\begin{array}{lll}0.4464 & 0.2898 & 0.2638\end{array}\right]$.

The above line vectors represent the evaluation value of a city's smart city construction project on the comment collection. It shows that the probability of good economic benefits of this item is $44.64 \%$, the probability of general economic benefits is $28.98 \%$, and the probability of poor economic benefits is $26.38 \%$. According to the principle of affiliation, the comprehensive evaluation of the evaluation items takes the rating level corresponding to the maximum value. The probability of good economic benefit of the project is $44.64 \%$, so we can determine that the overall evaluation of the economic benefit of the smart city construction project in this city is good. In addition, we should 


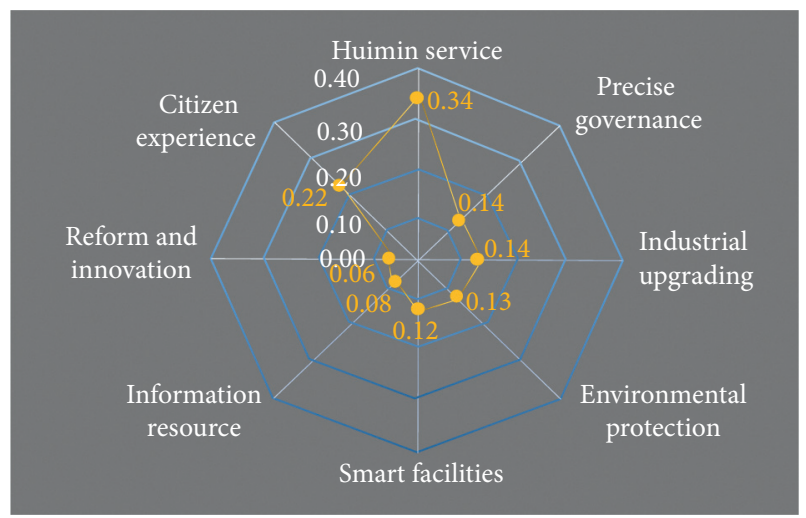

(a)

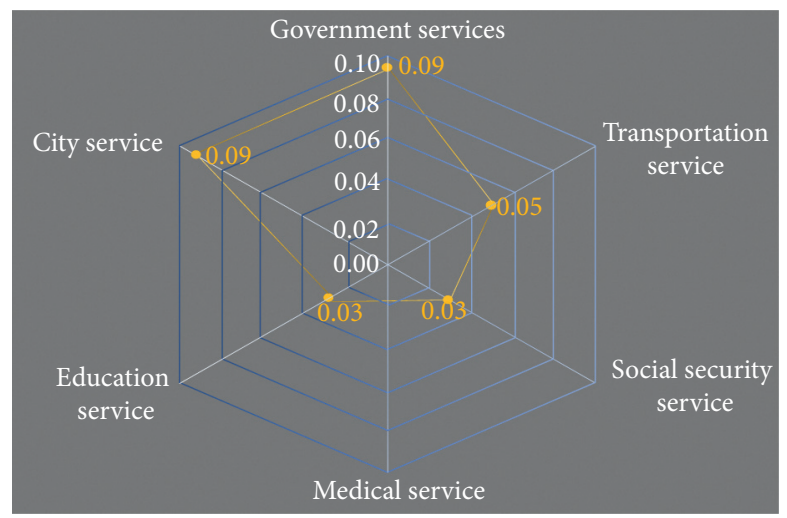

(b)

FIgURE 5: Radar chart of index combination weight in smart city.

also see that the project's economic efficiency is good or general probability is $73.62 \%$, greater than $50 \%$; this conclusion indicates that, at this stage of the preproject evaluation, the smart city complex construction project of the financial profitability and project risk are acceptable to the project investment body. Respectively, draw radar chart for index combination weight analysis, as shown in Figure 5.

From Figure 5(a), we can see that the service index for the benefit of the people has the largest weight in the first level index, followed by the citizen experience, and the sum of the weights of the two first level indexes exceeds $50 \%$, and the weight of reform and innovation is the smallest, which shows that the province and the city are people-oriented in the construction of new smart city, pay attention to people's experience and feelings, and serve the people wholeheartedly, which is also the purpose of new smart city construction. From Figure 5(b), it can be seen that, in the secondary indicators under the service for the benefit of the people index, the government service and city service index have the largest weight, and the social security service, education service, and medical service have the smallest and equal weight, which shows that the government service and city service have the greatest impact on the construction of the service for the benefit of the people in the new smart city at the county level. Only by first improving the level of government service and improving the governance capacity can we unify them. Only by planning for the construction of other information infrastructure such as urban services and transportation services can we ensure the smooth construction of the new smart city.

Analysing financial profitability, financial solvency, and uncertainty of the project in the financial evaluation and analysing the smart city complex construction project of the city in the payback period, the static payback period is 2.65 years, the dynamic payback period is 2.85 years, and the investment payback period is shorter and less than the project period, indicating that the project has a strong liquidity of return; a net present value greater than zero indicates that the project has strong profitability; the internal rate of return is $16.54 \%$, which is greater than the industry benchmark rate of return of $12 \%$, indicating that the project is economically viable. The scores of

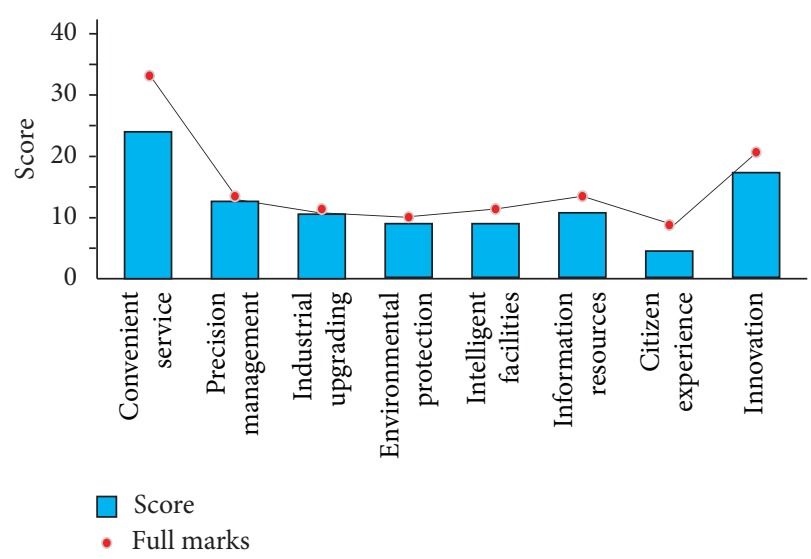

FIgURE 6: The scores of subindicators in the evaluation of smart city construction.

subindicators in the evaluation of smart city construction are shown in Figure 6.

It can be seen from Figure 6 that the service index for the benefit of the people has the highest score, followed by the citizen experience, and the relative score of reform and innovation is relatively low. However, considering the full score of each index, the city has done the best in precision governance, reaching the full score level, and the industrial upgrading, intelligent facilities, and reform and innovation are also close to the full score level, with good construction, followed by tourism and environmental protection. Although there are still some gaps between the service for the benefit of the people and the citizen experience index, the city has made good achievements in the service for the benefit of the people and the citizen experience, which is still in the growth period of the construction of a new smart city.

The evaluation of project risk mainly focuses on four indicators: policy risk, economic risk, technical risk, and social risk. The policy risk is mainly caused by the change, update, cancellation, or new promulgation of national and regional policies, regulations, or standards in the process of project implementation, which will cause changes in market demand or affect the cost and income of real estate projects; economic risk refers to the risk of uncertain income caused by the 
change of economic operation, which is mainly caused by a series of factors related to economic environment and development; social risk refers to the risk brought by the change of social environment factors to the project; technical risk refers to the risk caused by technical factors during the whole life cycle of the project [25]. According to the results of expert evaluation and market research, it can be found that the possibility of unexpected adverse risks of the four risk indicators is relatively low, the key influencing factors such as relevant policies, market demand, market price, engineering project technology, and urban development planning are basically stable and incline to the direction conducive to the healthy development of the real estate market, so the risk analysis and evaluation of the project is feasible.

The evaluation of the social benefits of the project mainly highlights the two indicators of improving the environment and promoting employment. The development of this project has a positive contribution to the urban construction. It meets the planning requirements in the development planning of the new urban area, and it beautifies the urban environment and promotes the urban construction. Improving the living environment of residents has a positive role in promoting. The smooth implementation of this project can effectively promote the employment of local residents, which not only is reflected in the employment of construction workers but also has a positive role in the development of the consumer market around the community, which will greatly increase the external benefits of industrialization and promotion of employment. The regional increase of employment rate, the promotion of regional economic development, and the living standards of employees who have been hired for business are farreaching.

\section{Conclusions}

Smart city is the inevitable trend of urban construction and development. In the process of urban modernization, the pressure on the city is increasing. The construction of smart city can better reduce the pressure on urban development. The construction of smart city needs to meet a variety of requirements; based on information technology, the efficient construction of different fields is inseparable from the acquisition and application of information in different fields. Data acquisition and data analysis, integration, and utilization with big data technology can provide more information resources for urban construction, which is conducive to the construction and development of smart city. Starting from the application of smart city, this paper analyses the impact of smart city planning and construction on economic and social benefits and puts forward the application effect and development trend of multisource spatial big data in these fields. In general, multisource spatial big data provides the information foundation for the construction of smart city by various ways and data acquisition methods, builds smart city model by data model, improves the construction effect of smart city, and better serves the construction of smart city application system. So as to realize the economic development, take into account the social livelihood and environmental protection, adhere to the people-oriented concept, create a smart city with science and technology to strengthen the government, jointly promote social progress, benefit the people with information, balance development in all aspects, and comprehensively improve the social benefits of the smart city. The construction of smart city is based on data. If there is no data, no data transmission, no data processing, no storage, and no reprocessing, do not mention intelligent management and intelligent construction, which are ignored in many places. In the future, with the gradual promotion and continuous operation of smart city construction, smart city industry will play a significant leading role in accelerating the transformation and upgrading of industrial structure, building a modern industrial system and the overall and long-term economic and social development.

\section{Data Availability}

The data used to support the findings of this study are available from the corresponding author upon request.

\section{Conflicts of Interest}

The authors declare that they have no known conflicts of financial interests or personal relationships that could have appeared to influence the work reported in this paper.

\section{References}

[1] S. J. Kim, L. A. March, and J. T. Hancock, "Scaling up research on drug abuse and addiction through social media big data," Journal of Medical Internet Research, vol. 19, no. 10, pp. 142-153, 2017.

[2] R. Mazhar, A. Awaits, and P. Anand, "Urban planning and building smart cities based on the internet of things using big data analytics," Computer Networks the International Journal of Computer \& Telecommunications Networking, vol. 10, no. 4, pp. 63-80, 2016.

[3] S. Console, V. Presto, and D. R. Recuperate, "Producing linked data for smart cities: the case of Catania," Big Data Research, vol. 12, no. 7, pp. 1-15, 2017.

[4] J. Y. Su, "Regional tendencies of research collaboration of social sciences in China: analysis based on papers of economic journals," Journal of Data and Information Science, vol. 7, no. 1, pp. 31-45, 2014.

[5] Z. Lv, T. Yin, X. Zhang, H. Song, and G. Chen, "Virtual reality smart city based on WebVRGIS," IEEE Internet of Things Journal, vol. 3, no. 6, pp. 1015-1024, 2016.

[6] Y. Chen and M. Takayasu, "Modeling of foreign exchange rate dynamics and simulation (big-data and simulations of social and economic systems-prospect of econophysics study)," Journal of the Japan Society for Simulation Technology, vol. 33, pp. 254-257, 2014.

[7] J. Darden, R. Malega, and R. Stallings, "Social and economic consequences of black residential segregation by neighbourhood socioeconomic characteristics: the case of metropolitan Detroit," Urban Studies, vol. 56, no. 1, pp. 115-130, 2019.

[8] W. L. Feng, Y. C. Duan, M. X. Huang, L. F. Dong, X. Y. Zhou, and $\mathrm{T}$. Hu, "A research on smart tourism service mechanism 
based on context awareness," Applied Mechanics and Materials, vol. 519-520, no. 9, pp. 752-758, 2014.

[9] M. Zhou, S. Lu, and Q. Liu, "Uniform regularity for a KellerSegel-Navier-Stokes system," Applied Mathematics Letters, vol. 107, Article ID 106476, 2020.

[10] V. Vimarlund and S. Wass, "Big data, smart homes and ambient assisted living," Yearbook of Medical Informatics, vol. 9, no. 1, pp. 143-149, 2014.

[11] S. Luis, L. Jorge, and S. Pablo, "Managing large amounts of data generated by a smart city internet of things deployment," International Journal on Semantic Web \& Information Systems, vol. 12, no. 4, pp. 22-24, 2016.

[12] T. Hashem, A. T. Ibrahim, and A. Victor, "The role of big data in smart city," International Journal of Information Management, vol. 36, no. 5, pp. 748-758, 2016.

[13] J. Yaqoob, Z. Ji, and M. Shi, "Scenario analysis and application research on big data in smart power distribution and consumption systems," Proceedings of the CSEE, vol. 35, no. 8, pp. 1829-1836, 2015.

[14] Y. B. Ren, G. Chen, Y. Han, and H. Zheng, "Extracting potential bus lines of customized city bus service based on public transport big data," IOP Conference Series: Earth and Environmental Science, vol. 46, no. 1, pp. 120-125, 2016.

[15] M. D. Litres, R. Vijay, and D. Ernesto, "Big data and data analytics research: from metaphors to value space for collective wisdom in human decision making and smart machines," International Journal on Semantic Web \& Information Systems, vol. 13, no. 1, pp. 1-10, 2017.

[16] F. R. Awed and S. A. Talab, "The prospective economic and social benefits of e-learning with special focusing on the Sudanese experience," International Journal of Computer Applications, vol. 10, no. 5, pp. 23-27, 2014.

[17] C. Sudesh and H. Eugene, "Research based on big data: the good, the bad, and the ugly," Journal of Thoracic and Cardiovascular Surgery, vol. 151, no. 3, pp. 629-630, 2015.

[18] B. W. Zhang, C. Y. Yan, and J. G. Bi, "Research on the architecture of electrical equipment status early warning system based on big data," Electric Power Information \& Communication Technology, vol. 12, no. 7, pp. 26-32, 2016.

[19] M. L. Yan, P. Z. Liu, and F. J. Wen, "Research on precision management of farming season based on big data," Eurasia Journal on Wireless Communications \& Networking, vol. 15, no. 6, pp. 143-145, 2018.

[20] M. Samian, H. Saudi, and M. Aadi, "The role of fishing cooperatives on social-economic and cultural development of rural areas of Bord Kuhn city of Bushehr, Iran," Journal of the Saudi Society of Agricultural Sciences, vol. 43, no. 3, pp. 442-448, 2015.

[21] H. Howard, G. Sandro, and R. Laura, "Big data and population health: focusing on the health impacts of the social, physical, and economic environment," Epidemiology, vol. 28, no. 6, pp. 759-762, 2017.

[22] N. Lee and J. J. Jung, "Content-based analytics of diffusion on social big data: a case study on Korean telecommunication companies," Schriftenreihe der Deutschemark Gesellschaft foer Geowissenschaften, vol. 13, no. 4, pp. 176-178, 2014.

[23] F. Q. Niu, Z. Q. Wang, and Y. Hu, "A model of urban spatial evolution process based on economic and social activities," Progress in Geography, vol. 34, no. 1, pp. 30-37, 2015.

[24] L. U. Li, Y. Zhang, and H. Tan, "Research on classification algorithm and concept drift based on big data," Journal of Frontiers of Computer Science \& Technology, vol. 10, no. 12, pp. 1683-1692, 2016.
[25] X. Y. Chen, S. Shao, and Z. H. Tian, "Impacts of air pollution and its spatial spill over effect on public health based on China's big data sample," Journal of Cleaner Production, vol. 142, pp. 915-925, 2016. 